\title{
Experimental study of convective condensation in an inclined smooth tube. Part II: Inclination effect on pressure drops and void fractions
}

\author{
Stéphane Lips, Josua P. Meyer* \\ Department of Mechanical and Aeronautical Engineering, University of Pretoria, Pretoria, 0002, South Africa
}

Keywords:

Convective condensation

Inclined two-phase flow

Pressure drop

Void fraction

\section{ABSTRACT}

This article is the second part of a two-part paper, dealing with an experimental study of convective condensation of R134a at a saturation temperature of $40^{\circ} \mathrm{C}$ in an $8.38 \mathrm{~mm}$ inner diameter smooth tube in inclined orientations. The first part concentrates on the flow pattern and the heat transfer coefficients. This second part presents the pressures drops in the test condenser for different mass fluxes and different vapour qualities for the whole range of inclination angles (downwards and upwards). Pressures drops in a horizontal orientation were compared with correlations available in literature. In a vertical orientation, the experimental results were compared with pressure drop correlations associated with void fraction correlations available in literature. A good agreement was found for vertical upward flows but no correlation predicted correctly the measurements for downward flows. An apparent gravitational pressure drop and an apparent void fraction were defined in order to study the inclination effect on the flow. For upward flows, it seems as if the void fraction and the frictional pressure drop are independent of the inclination angle. Apparent void fractions were successfully compared with correlations in literature. This was not the case for downward flows. The experimental results for stratified downward flows were also successfully compared with the model of Taitel and Dukler.

\footnotetext{
* Corresponding author. Tel.: +27 (0)12 420 3104; Fax: +27 (0)12 3625124

E-mail address: josua.meyer@up.ac.za
} 


\section{Nomenclature}

$\begin{array}{ll}A & \text { Cross-sectional area }\left(\mathrm{m}^{2}\right) \\ g & \text { Gravitational acceleration }\left(\mathrm{m} / \mathrm{s}^{2}\right) \\ G & \text { Mass flux }\left(\mathrm{kg} / \mathrm{m}^{2} \mathrm{~s}\right) \\ L & \text { Length of the tube }(\mathrm{m}) \\ L_{\Delta P} & \text { Distance between the pressure taps }(\mathrm{m}) \\ P & \text { Pressure }(\mathrm{Pa}) \\ S & \text { Length of the interface }\left(\mathrm{m}^{2}\right) \\ x & \text { Vapour quality }(-) \\ & \text { Greek symbols } \\ \beta & \text { Inclination angle }(>0: \text { upward })(\mathrm{rad}) \\ \varepsilon & \text { Void fraction }(-) \\ \rho & \text { Density }\left(\mathrm{kg} / \mathrm{m}^{3}\right) \\ \sigma & \text { Surface tension }(\mathrm{N} / \mathrm{m}) \\ \tau & \text { Shear stress }(\mathrm{Pa}) \\ & \\ & \text { Subscripts } \\ e q & \text { Equivalent } \\ \text { fric } & \text { Frictional }\end{array}$

$\begin{array}{ll}\text { grav } & \text { Gravitational } \\ h & \text { Homogeneous } \\ i & \text { Interface } \\ \text { in } & \text { Inlet } \\ l & \text { Liquid } \\ \text { lines } & \text { Lines between pressure taps and } \\ \text { transducer } & \\ \text { meas } & \text { Measurement } \\ \text { mom } & \text { Momentum } \\ r h & \text { Rouhani and Axelsson } \\ \text { out } & \text { Outlet } \\ \text { sat } & \text { Saturation } \\ \text { test } & \text { Test condenser } \\ v & \text { Vapour } \\ w & \text { Wall } \\ & \\ * & \text { Superscripts } \\ & \text { Apparent }\end{array}$

\section{Introduction}

The design of condensers in industrial applications requires predictive tools for the pressure drop that occurs in the tubes. Pressure drop affects the saturation temperature of the refrigerant and thus can significantly reduce the efficiency of the system [1]. Pressure drops during convective condensation or evaporation in horizontal tubes were studied by several research teams in the last 10 years. Ould Didi et al. [2] compared their experimental pressure drop results with different correlations available in the literature. Five different refrigerants were used for a total of 788 data points obtained during the evaporation of refrigerants in smooth horizontal tubes. They found that the method of Müller-Steinhagen and Heck [3] was the best for annular flows while the method of Grönnerud [4] gave the best predictions for both intermittent and stratified-wavy flows. All the correlations tested were developed for gas-liquid flow and do not take into account the effect of the phase change. To improve these correlations, Cavallini et al. [5] applied the correction factor of Mickley [6] during the condensation of a refrigerant inside a tube. More recently, Moreno Quibén and Thome $[7,8]$ published a flow pattern-based two-phase frictional pressure drop model for horizontal tubes. Studies on pressure drops have also been conducted for enhanced tubes $[9,10]$.

Few studies about pressure drop during condensation in vertical tubes are available in the literature. Experimental data obtained for these conditions are often compared with pressure drop correlations for adiabatic gas-liquid flow. Kim and No [11] compared their experimental results with the predictions of the modified Nusselt theory [12]. They found that the model underpredicted the pressure drop by about 25\%. Dalkilic et al. [13] compared 13 two-phase pressure drop correlations with their experimental results obtained with condensing R134a in a vertical tube (downward flow) at 
a high mass flux. They found that the model of Cavallini et al. [5] and the model of Chen et al. [14] predicted the experimental pressure drop well. Both correlations were developed for a horizontal orientation. However, the comparison of experimental data with pressure drop correlations requires the calculation of the gravitational and the momentum pressure drops. Dalkilic et al. [15] showed that the choice of the void fraction model has a strong effect on the two-phase friction factor.

Experimental studies on pressure drops and void fractions in inclined tubes are very rare, as indicated in a previous paper by Lips and Meyer [16]. Würfel et al. [17] presented an experimental study of two-phase flows inside an inclined tube $\left(20 \mathrm{~mm}\right.$ inner diameter, angle of inclination: $0^{\circ}, 11^{\circ}$, $30^{\circ}, 45^{\circ}, 90^{\circ}$ ). They measured two-phase friction coefficients, local thicknesses, void fractions and entrainments for a gas-vapour flow (air-n-heptane) and heat transfer coefficients during condensation of n-heptane in downward flows. They concluded that the inclination angle has no effect on the pressure drop. Beggs and Brill [18] proposed a correlation to predict the void fraction for all inclination angles (both downward and upward flows). However, data were collected for air-water flow in $25 \mathrm{~mm}$ and $38 \mathrm{~mm}$ diameter tubes and thus the proposed correlation cannot be extrapolated for condensation of refrigerant in an $8.38 \mathrm{~mm}$ inner diameter tube.

In conclusion, there is a lack of predictive models to determine the pressure drops in inclined tubes during convective condensation of refrigerant, especially because of the need to know the void fraction as a function of the inclination angle. The effect of the condensation process is not clear as most of the correlations presented in the literature were developed for adiabatic gas-liquid flows.

The purpose of this paper is to get a better understanding of the different phenomena that affect the pressure drops during convective condensation of refrigerant in inclined tubes. In the first part [19] of this two-part paper, an experimental study of flow patterns and heat transfer coefficients during convective condensation in an inclined tube was presented. This second part is dedicated to the study of the pressure drops and void fractions in the same experimental set-up at the same conditions reported in the first part.

\section{Data reduction and experimental procedure}

The details of the experimental facility and test condenser were discussed in detail in Part I by Lips and Meyer [19] and will not be repeated here. Pressure taps were inserted between the test condenser and the sight glasses at each end of the test condenser, which is described in Part I (Fig. 1) of this paper. The distance between the two pressure taps was equal to $L_{\Delta \mathrm{P}}=1704 \pm 2 \mathrm{~mm}$. An FP2000 Sensotec differential pressure transducer, calibrated to an accuracy of $50 \mathrm{~Pa}$, was used to measure the pressure drops inside the inner tube of the test condenser. The pressure lines between the taps and the transducer were heated with a heating wire to avoid condensation in the lines. The electrical power dissipated in the heating wire was controlled by four thermocouples and a Labview program, which 
ensured that the temperature of the lines was between $5^{\circ} \mathrm{C}$ and $10^{\circ} \mathrm{C}$ higher than the saturation temperature of the refrigerant in the test condenser.

The actual pressure drops in the test condenser, $\Delta P_{\text {test}}$, can be deduced for the raw measurements of the pressure transducer, $\Delta P_{\text {meas}}$, and a correction $\Delta P_{\text {lines, }}$, which depends on the inclination angle:

$$
\Delta P_{\text {test }}=\Delta P_{\text {meas }}+\Delta P_{\text {lines }}
$$

As the refrigerant is fully vapour in the pressure lines, the pressure drop in the lines can be depicted as:

$$
\Delta P_{\text {lines }}=\rho_{v} g L_{\Delta P} \sin \beta
$$

where $\beta$ is the inclination angle of the test condenser. $\beta$ is positive for upward flows and negative for downward flows.

The pressure drops in the test condenser were recorded for the same experimental conditions summarised in part I (Fig. 2) of this paper in terms of mass fluxes $G$ and vapour qualities $x$. In horizontal orientation, the conditions correspond to intermittent and annular flow patterns at the boundary of the stratified flow regime of the Thome-El Hajal-Cavallini [20] map. For each data point, the measurements were realised for different inclination angles. The FP2000 Sensotec differential pressure transducer was calibrated to an accuracy of $50 \mathrm{~Pa}$. During all the experiments, the saturation temperature and the heat transfer rate in the test condenser were kept constant at $40 \pm 0.5^{\circ} \mathrm{C}$ and $200 \pm 5 \mathrm{~W}$ respectively.

\section{Effect of inclination angle on pressure drops and void fractions}

\subsection{Experimental study of pressure drops}

The pressure drops measured in the test condenser as a function of the inclination angle are plotted in Fig. 1 for $G=300 \mathrm{~kg} / \mathrm{m}^{2} \mathrm{~s}$ and for different vapour qualities. An angle of $-90^{\circ}$ is for vertical downward flow, $0^{\circ}$ is for horizontal flow and $+90^{\circ}$ is for vertical upward flow. The pressure drops increase when the inclination angle increases because of the gravitational pressure drop. We can note that the increase is stronger for upward flows than for downward flows. Furthermore, the smaller the vapour quality, the stronger the increase of the pressure drops with the inclination angle. For the horizontal and vertical downward orientations, the pressure drops increase when the vapour quality increases. However, for vertical upward orientation, the pressure drops decrease when the vapour quality increases.

Fig. 2 gives the pressure drops as a function of the inclination angle for different mass fluxes and for $x=0.5$. The different curves follow the same trend for different mass fluxes. The pressure drops increase when the mass flux increases and for upward flows. However, the relative inclination effect on the pressure drop is almost independent of the mass flow. 
It is commonly admitted in the literature that the measured pressure drops, $\Delta P_{\text {test }}$, are the sum of three different terms: the gravitational pressure drop, $\Delta P_{\text {grav }}$, the momentum pressure drop, $\Delta P_{\text {mom }}$, and the frictional pressure drop, $\Delta P_{\text {fric }}$ :

$$
\Delta P_{\text {test }}=\Delta P_{\text {mom }}+\Delta P_{\text {grav }}+\Delta P_{\text {fric }}
$$

The momentum pressure drop depends on the kinetic energy at the inlet and outlet of the tube and thus on the void fraction as a function of the vapour quality, which depends on the inclination angle:

$$
\Delta P_{\text {mom }}=G^{2}\left[\left(\frac{(1-x)^{2}}{\rho_{l}(1-\varepsilon)}+\frac{x^{2}}{\rho_{v} \varepsilon}\right)_{\text {out }}-\left(\frac{(1-x)^{2}}{\rho_{l}(1-\varepsilon)}+\frac{x^{2}}{\rho_{v} \varepsilon}\right)_{\text {in }}\right]
$$

The subscripts in and out refer to the inlet and outlet of the tube respectively. The gravitational pressure drop is directly linked to the inclination angle $\beta$ of the tube.

$$
\Delta P_{\text {grav }}=\rho_{\text {eq }} g L_{\Delta P} \sin \beta
$$

where $\rho_{e q}$ is the equivalent density of the fluid. Considering the homogeneous model, it can be written as:

$$
\rho_{e q}=\rho_{l}(1-\varepsilon)+\rho_{v} \varepsilon
$$

The frictional pressure drop depends on the flow pattern and thus can also depend on the inclination angle of the pipe.

The determination of the gravitational, momentum and frictional pressure drops from the measurements requires knowing the void fraction in the flow. However, measuring directly and accurately the void fraction in two-phase flows is complicated and has not been done in this study. According to Thome [21], the momentum pressure drop can be calculated using Steiner's [22] version of the Rouhani and Axelsson [23] drift flux model:

$$
\varepsilon_{r h}=\frac{x}{\rho_{v}}\left[(1+0.12(1-x))\left(\frac{x}{\rho_{v}}+\frac{1-x}{\rho_{l}}\right)+\frac{1.18(1-x)\left[g \sigma\left(\rho_{l}-\rho_{v}\right)\right]^{0.25}}{G \rho_{l}^{0.5}}\right]^{-1}
$$

For the experimental conditions in the present study, the momentum pressure drop calculated with this correlation was always lower than $10 \%$ of the frictional pressure drop, so the choice of void fraction correlation is not of great importance for the momentum pressure drop determination. Note that, as stated by Dalkilic et al. [15], the choice of the void fraction correlation is of great importance for determining the gravitational pressure drop.

For the horizontal orientation, the gravitational pressure drop is equal to zero, whatever the void fraction, so it is possible to determine the frictional pressure drops. Fig. 3 represents a comparison between the experimental frictional pressure drops in horizontal orientation and the predictions of several correlations and models published in the literature. The model of Moreno Quibén and Thome [8] best represents the experimental results. This model is a flow pattern-based correlation and was developed for adiabatic flows and for convective evaporation in smooth tubes. In this study, it was used with the flow pattern map of El Hajal at al. [20] to predict the flow pattern 
during convective condensation. The other correlations presented in Fig. 3 were developed for adiabatic flows and mostly for annular flow patterns. The correlation of Friedel [24] and the one of Grönnerud [4] agree well with the experiments whereas the correlation of Chisholm [25] gives good results for high pressure drops only, which correspond to annular flow pattern. The homogeneous model, the correlations of Müller-Steinhagen and Heck [3] and those of Lockart-Martinelli [26] show a higher discrepancy between the predictions and the measurements.

Several correlations were developed to predict the pressure drops in vertical tubes, especially for upward flows. However, to be able to compare the experimental results with these correlations, we have to determine the gravitational pressure drops and thus choose a void fraction correlation. Fig. 4 represents the comparison of the experimental results for the vertical upward orientation with five different models. The homogeneous model [21] predicts both the void fraction and the pressure drops. The correlation of Friedel for vertical upward flow [24] is used with the void fraction correlation of Rouhani and Axelsson [23]. The void fraction correlation of Chisholm [25] is used with the pressure drop correlations of Chisholm [25], Chen et al. [14] and Cavallini et al. [5]. All the correlations represent the experimental results well, except the homogeneous model, which is not valid for flows with a slip ratio not equal to one, which is the case in the present study. The good agreement shows that the gravitational pressure drops, and thus the void fraction, for upward flows are predicted well by the void fraction correlations.

There are few studies dealing with vertical downward flows, comparatively to vertical upward flows. Fig. 5 represents the comparison between the experimental results and the same correlations as those presented in Fig. 4. Only the Friedel correlation was adapted to the one developed for downward vertical flows [24]. The Friedel and Chisholm correlations predict quite well the experimental results for high-pressure drops (i.e. high mass fluxes and high vapour qualities), but none of the correlations are able to predict the whole range of pressure drops encountered in the experiments. The correlations underestimate the pressure drops: it means that they overestimate the gravitational pressure and they underestimate the void fraction for two-phase flow in vertical downward tubes.

It has previously been noticed that it is not possible to separate the frictional pressure drop and the gravitational pressure drop from the experimental measurements. However, we can define an apparent gravitational pressure drop, $\Delta P_{g r a v}^{*}$, which is the difference between the pressure drops in inclined and horizontal orientation:

$$
\Delta P_{\text {grav }}^{*}=\Delta P_{\text {test }}-\left(\Delta P_{\text {test }}\right)_{\beta=0^{\circ}}
$$

The apparent gravitational pressure drop is equal to the actual gravitational pressure drop only if the frictional and momentum pressure drops remain constant, whatever the angle of inclination. Fig. 6 represents the apparent gravitational pressure drop as a function of the sinus of the inclination angle for $G=300 \mathrm{~kg} / \mathrm{m}^{2} \mathrm{~s}$ and for different vapour qualities. For upward flows, the apparent gravitational pressure drops increase linearly with the sinus of the inclination angles. If we assume that the 
frictional pressure drop remains constant in these conditions and according to Eq. (5), it can mean that the void fraction remains constant, whatever the inclination angle. However, it is not possible to verify this assumption with the present experimental set-up and it is also possible that the frictional pressure drop variation compensates the void fraction variation. A void fraction sensor is required to confirm this assumption. The apparent gravitational pressure drop also logically increases when the vapour quality decreases as it leads to a decrease of the void fraction. For downward flows, the evolution of the apparent gravitational pressure drops is no longer linear with the sinus of the inclination angle. It shows that the frictional pressure drops and/or the void fraction are dependent on the angle of inclination. Note also that the lowest vapour quality $(x=0.1)$ does not lead to the highest apparent gravitational pressure drop (in absolute value).

Fig. 7 represents the effect of the mass fluxes on the apparent gravitational pressure drops: the apparent gravitational pressure drop as a function of the sinus of the inclination angle is plotted for 3 mass fluxes and for 3 vapour qualities. As for Fig. 6, the behaviour of the flow is different for upward and downward flows: for upward flows, the apparent gravitational pressure drops are almost insensitive to the mass flux. On the contrary, for downward flows, the mass flux has a noticeable effect on the pressure drops.

The difference of behaviour between downward and upward flows can be explained by the flow pattern analysis presented in the first part of the article. For upward flows, the flow pattern is mainly intermittent or annular. For intermittent flows, there is a strong interaction between the liquid and the vapour phase: the inclination angle has a weak effect on this interaction and the frictional pressure drops and the void fraction remain constant. Annular flows are mainly lead by shear forces and the gravitational forces are negligible. As a consequence, the inclination angle has also almost no effect on the flow properties. Furthermore, for these two flow patterns, the void fraction is almost insensitive to the mass flux. On the contrary, for downward flows, stratified flows occur: this kind of flow is strongly dependent on the gravitational forces and thus on the inclination angle of the tube. As a consequence, the slip ratio between the phases, the void fraction and the frictional pressure drops strongly depend on the inclination angle.

\subsection{Theoretical study of the void fraction}

From the apparent gravitational pressure drop, it is possible to determine an apparent void fraction, which is defined as the void fraction that would have led to the apparent gravitational pressure drop:

where $\rho^{*}$ is the apparent density of the flow:

$$
\varepsilon^{*}=\frac{\rho_{l}-\rho^{*}}{\rho_{l}-\rho_{v}}
$$

$$
\rho^{*}=\frac{\Delta P_{g r a v}^{*}}{g L_{\Delta P} \sin \beta}
$$


The apparent void fraction is equal to the actual void fraction only if the frictional pressure drops for the inclined orientation are the same as those for the horizontal orientation. However, keeping this limitation in mind, it is interesting to study the apparent void fraction as a function of the inclination angle. It is plotted in Fig. 8 for $G=300 \mathrm{~kg} / \mathrm{m}^{2} \mathrm{~s}$ and for different vapour qualities. For upward flows, the apparent void fraction can be considered constant, at least for a void fraction higher than 0.25. For downward flows, the apparent void fraction increases when the inclination angle increases. For each curve, three markers representing different correlations are plotted. For $\beta=0^{\circ}$, the marker represent the value of the Steiner [22] version of the correlation of Rouhani and Axelsson [23]. This correlation was developed for horizontal flows. The void fraction correlation of Chisholm [25], which is supposed to be independent of the tube orientation, is plotted for $\beta=45^{\circ}$. Lastly, the Rouhani and Axelsson correlation for vertical tubes [23] is plotted for $\beta=90^{\circ}$. Note that the different correlations and the apparent void fraction for upward flows follow the same trends. Thus, it would be interesting to further investigate the link between the apparent and the actual void fraction. In the same figure is plotted in thick lines the mean apparent void fraction for upward flows, which is determined by doing a linear regression of the apparent gravitational pressure drop as a function of the sinus of the inclination angle. The range of inclination angles used for the linear regression is $-5^{\circ}$ to $90^{\circ}$, which corresponds to the range where the curves can be considered as linear. Equations (9) and (10) are then used to calculate the mean apparent void fraction. Fig. 9 represents the same type of curve than that in Fig. 8 but for three different mass fluxes and three different vapour qualities. This graph confirms the fact that the mass flux has almost no influence on the apparent void fraction as well as on the void fractions predicted by the correlations.

As for the apparent gravitational pressure drop, different behaviours can be distinguished in terms of apparent void fractions: for upward flows, the apparent void fraction is almost independent of the inclination angle whereas it depends strongly on the inclination angle for downward flows and low vapour qualities. For high vapour qualities, the apparent void fractions remain almost constant whatever the tube orientation. By means of the observations presented in part I of the present article, it is possible to link these three types of behaviour to the three main types of flow patterns, namely intermittent, stratified and annular flows respectively. The strongest variation of the apparent void fraction is encountered for low mass fluxes when the tube orientation varies from slightly downwards to slightly upwards. It corresponds to the modification of the flow pattern from stratified to intermittent (Fig. 4, part I).

The experimental mean apparent void fractions for upward flows are plotted in Fig. 10 as a function of the vapour quality for $G=300 \mathrm{~kg} / \mathrm{m}^{2}$. The void fractions predicted by different correlations are also presented. A good agreement is observed between the experimental results and the correlations of Friedel [24] and Chisholm [25]. Note that the LMTD void fraction correlation [21], used by El Hajal et al. [20] for the flow pattern and heat transfer [27] models of convective condensation in horizontal tubes, does not represent the measurements well. 
In conclusion, the apparent void fraction may be a possible estimation of the actual void fraction for upward flows. The linearity of the apparent gravitational pressure drops as a function of the sinus of the inclination angle tends to show that the frictional pressure drops and the void fraction can be considered constant in these conditions. This is not the case for downward flows where the inclination angle has a stronger influence on the flow pattern and thus on the frictional pressure drop and void fraction. Thus, for downward flows, the apparent void fraction has not really any physical significance. A specific analysis has to be conducted for these configurations, especially to understand the inclination effect on stratified flows.

\subsection{Specification of stratified flows}

The most-used model for stratified flows in inclined tubes is that of Taitel and Dukler [28]. The model assumes a smooth stratified flow with a flat liquid-vapour interface. The momentum balance on the vapour phase yields:

$$
A_{v}\left(-\frac{d P}{d L}\right)_{v}=\tau_{v w} S_{v}+\tau_{i} S_{i}+A_{v} \rho_{v} g \sin \beta
$$

and for the liquid phase, it gives:

$$
A_{l}\left(-\frac{d P}{d L}\right)_{l}=\tau_{l w} S_{l}-\tau_{i} S_{i}+A_{l} \rho_{l} g \sin \beta
$$

Taitel and Dukler [28] showed that it is possible to solve these equations considering that the liquid is immobile compared to the vapour, which leads to $\tau_{i}=\tau_{v w}$. This model allows the calculation of the pressure drop for two-phase flows in slightly inclined tubes. We can compare the prediction of the model with experimental results only for stratified flows, i.e. for low vapour qualities and low mass fluxes. In our experimental database, two sets of conditions led to stratified flows: $G=200$ $\mathrm{kg} / \mathrm{m}^{2} \mathrm{~s}$ with $x=0.25$ for $-45^{\circ} \leq \beta \leq-5^{\circ}$ and $G=300 \mathrm{~kg} / \mathrm{m}^{2} \mathrm{~s}$ with $x=0.1$ for $-20^{\circ} \leq \beta \leq-5^{\circ}$. The comparison between the experimental pressure drops and the ones calculated by the Taitel and Dukler model is presented in Fig. 11 for $G=200 \mathrm{~kg} / \mathrm{m}^{2} \mathrm{~s}$ and $x=0.25$ and in Fig. 12 for $G=300 \mathrm{~kg} / \mathrm{m}^{2} \mathrm{~s}$ and $x$ $=0.1$. The experimental pressure drop is the sum of the gravitational and frictional pressure drops, i.e. the measured pressure drop minus the momentum pressure drop. Although the model has not been developed for condensing flows, there is a good agreement between the model and the experiments for the data point situated in the stratified flow regime.

The model of Taitel and Dukler [28] also allows determining the liquid hold-up and the void fraction in the tube. The liquid hold-up is defined as the ratio between the height of liquid in the tube and the tube diameter. A comparison between the flow visualisation and the liquid hold-up predicted by the model of Taitel and Dukler is represented in Fig. 13. The pictures represent an image of the average height of liquid in the tube and the lines represent the prediction of the model between $\beta=-60^{\circ}$ and $\beta=15^{\circ}$. Although the liquid-vapour interface is wavy, we can note a good agreement between the model and the visualisations. Note that for $\beta=15^{\circ}$, the flow is intermittent (the model of 
Taitel and Dukler is not valid anymore as it was developed for stratified flows) and the images do not represent the average liquid height in the tube well, as can be expected. For $\beta=-60^{\circ}$, the liquid-vapour interface is curved and thus the assumption of a flat interface in the Taitel and Dukler model is not verified. The extension of this model for the whole range of inclination angles by taking into account the curvature of the liquid-vapour interface would be a real improvement. This would allow the prediction of a smooth transition between stratified and annular flow patterns.

Fig. 14 represents a comparison between the model (Eq. (9)) and the experimental apparent void fraction determined for the data points corresponding to stratified flows. Although the pressure drops (Fig. 11 and Fig. 12) and the liquid hold-up predictions (Fig. 13) agree with the experiments, the apparent void fraction and the predicted void fractions do not correspond well. This can be due to the fact that the apparent void fraction does not represent the actual void fraction in the flow. The frictional pressure drop cannot be considered independent of the inclination angle. Note that no distinction can be made between frictional and gravitational pressure drop in the Taitel and Dukler model as the two phases are considered separate and the gravitational forces applied differently for each phase. This highlights the necessity to implement a void fraction sensor in the test section in order to further study pressure drops for two-phase flows in inclined tubes.

\section{Conclusions}

Convective condensation experiments were conducted in a smooth inclined tube for a range of inclination angles. R134a at a saturation temperature of $40^{\circ} \mathrm{C}$ was used, mass fluxes and vapour qualities ranging from 200 to $600 \mathrm{~kg} / \mathrm{m}^{2} \mathrm{~s}$ and 0.1 to 0.9 respectively.

The inclination effect on the pressure drops was studied experimentally and the results were compared with different correlations available in the literature for the horizontal and vertical orientations. For horizontal orientation, the model of Moreno Quibén and Thome [8] used with the flow pattern map of El-Hajal et al. [20] for convective condensation best represents the experimental results. The correlation of Friedel [24] and that of Grönnerud [4] also gave good results. For the comparison of pressure drops in vertical tubes, a void fraction correlation had to be chosen. The determination of the momentum and gravitational pressure drop requires the knowledge of the void fraction. The different correlations tested gave a good agreement with experimental data for upward flows but failed to predict the pressure drops during downward flows.

A theoretical analysis of the void fraction was also conducted. An apparent void fraction was calculated from the apparent gravitational pressure drops. It appears that for upward flows the void fraction can be considered constant and the correlations available in the literature represent the experimental results well. For downward flows, the apparent void fraction cannot be considered an estimation of the actual void fraction as the frictional pressure drops seem to depend on the inclination angle. 
For slightly inclined orientations and especially for downward flows, the experimental results were compared successfully with the model of Taitel and Dukler [28] in terms of pressure drops. However, this model is limited to stratified flows.

This article highlights the necessity to insert a void fraction sensor in the experimental set-up in order to have a better comprehension of the effect of the inclination angle on the pressure drops and void fractions during convective condensation in inclined tubes.

\section{Acknowledgements}

The funding obtained from the NRF, TESP, University of Stellenbosch/University of Pretoria, SANERI/SANEDI, CSIR, EEDSM Hub and NAC is acknowledged and duly appreciated.

\section{References}

[1] A. Cavallini, J.S. Brown, D. Del Col, C. Zilio, In-tube condensation performance of refrigerants considering penalization terms (exergy losses) for heat transfer and pressure drop, Int. J. Heat Mass Transfer. 53 (2010) 2885-2896.

[2] M.B. Ould Didi, N. Kattan, J.R. Thome, Prediction of two-phase pressure gradients of refrigerants in horizontal tubes, Int. J. Refrig. 25 (2002) 935-947.

[3] H. Müller-Steinhagen, K. Heck, A simple friction pressure drop correlation for two-phase flow in pipes, Chem. Eng. Process. 20 (1986) 297-308.

[4] R. Grönnerud, Investigation of liquid hold-up, flow-resistance and heat transfer in circulation type evaporators. Part IV: Two-phase flow resistance in boiling refrigerants, Bull. De l'Inst. Du Froid, Annexe. 1 (1972).

[5] A. Cavallini, G. Censi, D. Del Col, L. Doretti, G.A. Longo, L. Rossetto, Experimental investigation on condensation heat transfer and pressure drop of new HFC refrigerants (R134a, R125, R32, R410A, R236ea) in a horizontal smooth tube, Int. J. Refrig. 24 (2001) 73-87.

[6] H.S. Mickley, R.C. Ross, A.L. Squyers, W.E. Stewart, Heat, mass, and momentum transfer for flow over a flat plate with blowing or suction, NACA-TN-3208, Massachusetts Inst. of Tech., 1953.

[7] J. Moreno Quibén, J.R. Thome, Flow pattern based two-phase frictional pressure drop model for horizontal tubes. Part I: Diabatic and adiabatic experimental study, Int. J. Heat Fluid Flow. 28 (2007) 1049-1059.

[8] J. Moreno Quibén, J.R. Thome, Flow pattern based two-phase frictional pressure drop model for horizontal tubes. Part II: New phenomenological model, Int. J. Heat Fluid Flow. 28 (2007) 1060-1072.

[9] A. Cavallini, D. Del Col, L. Doretti, G.A. Longo, L. Rossetto, Heat transfer and pressure drop during condensation of refrigerants inside horizontal enhanced tubes, Int. J. Refrig. 23 (2000) 4-25.

[10] J.A. Olivier, L. Liebenberg, M.A. Kedzierski, J.P. Meyer, Pressure Drop During Refrigerant Condensation Inside Horizontal Smooth, Helical Microfin, and Herringbone Microfin Tubes, J. Heat Transfer. 126 (2004) 687-696.

[11] S.J. Kim, H.C. No, Turbulent film condensation of high pressure steam in a vertical tube, Int. J. Heat Mass Transfer. 43 (2000) 4031-4042.

[12] V.P. Carey, Liquid-vapor phase-change phenomena, Hemisphere, New York, 
1992.

[13] A.S. Dalkilic, O. Agra, I. Teke, S. Wongwises, Comparison of frictional pressure drop models during annular flow condensation of R600a in a horizontal tube at low mass flux and of R134a in a vertical tube at high mass flux, Int. J. Heat Mass Transfer. 53 (2010) 2052-2064.

[14] I.Y. Chen, K.S. Yang, Y.J. Chang, C.C. Wang, Two-phase pressure drop of air-water and R-410A in small horizontal tubes, Int. J. Multiphase Flow. 27 (2001) 12931299.

[15] A.S. Dalkilic, S. Laohalertdecha, S. Wongwises, Effect of void fraction models on the two-phase friction factor of R134a during condensation in vertical downward flow in a smooth tube, Int. Commun. Heat Mass Transfer. 35 (2008) 921-927.

[16] S. Lips, J.P. Meyer, Two-phase flow in inclined tubes with specific reference to condensation: A review, Int. J. Multiphase Flow. 37 (2011) 845-859.

[17] R. Würfel, T. Kreutzer, W. Fratzscher, Turbulence transfer processes in adiabatic and condensing film flow in an inclined tube, Chem. Eng. Technol. 26 (2003) 439448.

[18] D.H. Beggs, J.P. Brill, A study of two-phase flow in inclined pipes, J. Pet. Technol. 25 (1973).

[19] S. Lips, J.P. Meyer, Experimental study of convective condensation in an inclined smooth tube. Part I: Inclination effect on flow pattern and heat transfer coefficient, Int. J. Heat Mass Transfer. (2011) Submitted for review.

[20] J. El Hajal, J.R. Thome, A. Cavallini, Condensation in horizontal tubes. Part 1: two-phase flow pattern map, Int. J. Heat Mass Transfer. 46 (2003) 3349-3363.

(2006).

[21] J.R. Thome, Engineering Data Book III, Huntsville, AL: Wolverine Tube, Inc.

[22] D. Steiner, Heat transfer to boiling saturated liquids, VDI-Wārmeatlas (VDI Heat Atlas), Verein Deutscher Ingenieure, VDI-Gesellschaft Verfahrenstechnik Und Chemieingenieurwesen (GCV), Düsseldorf, Chapter Hbb. (1993).

[23] S.Z. Rouhani, E. Axelsson, Calculation of void volume fraction in the subcooled and quality boiling regions, Int. J. Heat Mass Transfer. 13 (1970) 383-393.

[24] L. Friedel, Improved friction pressure drop correlations for horizontal and vertical two-phase pipe flow, dans: European Two-phase Flow Group Meeting, Paper E, 1979.

[25] D. Chisholm, Pressure gradients due to friction during the flow of evaporating two-phase mixtures in smooth tubes and channels, Int. J. Heat Mass Transfer. 16 (1973) 347358.

[26] R.W. Lockhart, R.C. Martinelli, Proposed correlation of data for isothermal two-phase, two-component flow in pipes, Chem. Eng. Prog. 45 (1949) 39-48.

[27] J.R. Thome, J. El Hajal, A. Cavallini, Condensation in horizontal tubes. Part 2: new heat transfer model based on flow regimes, Int. J. Heat Mass Transfer. 46 (2003) 3365 3387.

[28] Y. Taitel, A.E. Dukler, A model for predicting flow regime transitions in horizontal and near horizontal gas-liquid flow, AIChE J. 22 (1976) 47-55. 


\section{List of figure captions}

Fig. 1. Measured pressure drops for different vapour qualities $\left(G=300 \mathrm{~kg} / \mathrm{m}^{2} \mathrm{~s}\right)$.

Fig. 2. Measured pressure drops for different mass fluxes $(x=0.5)$.

Fig. 3. Comparison of experimental pressure drops with different correlations for horizontal flow.

Fig. 4. Comparison of experimental pressure drops with different correlations for vertical upward flow.

Fig. 5. Comparison of experimental pressure drops with different correlations for vertical downward flow.

Fig. 6. Apparent gravitational pressure drops for different vapour qualities as a function of inclination angle $\left(G=300 \mathrm{~kg} / \mathrm{m}^{2} \mathrm{~s}\right)$.

Fig. 7. Effect of the mass flux on the apparent gravitational pressure drop as a function of inclination angle.

Fig. 8. Effect of inclination angle on the apparent void fraction and comparison with different correlations $\left(G=300 \mathrm{~kg} / \mathrm{m}^{2} \mathrm{~s}\right)$. The thick horizontal lines represent the mean apparent void fraction between $-5^{\circ}$ and $90^{\circ}$.

Fig. 9. Effect of the mass flux on the apparent void fraction. The thick horizontal lines represent the mean apparent void fraction between $-5^{\circ}$ and $90^{\circ}$.

Fig. 10. Apparent void fraction for horizontal and upward flows and comparison with different correlations $\left(G=300 \mathrm{~kg} / \mathrm{m}^{2} \mathrm{~s}\right)$.

Fig. 11. Pressure drops predicted by the model of Taitel and Dukler compared with experimental results $\left(\mathrm{G}=200 \mathrm{~kg} / \mathrm{m}^{2} \mathrm{~s} ; \mathrm{x}=0.25\right)$.

Fig. 12. Pressure drops predicted by the model of Taitel and Dukler compared with experimental results $\left(\mathrm{G}=300 \mathrm{~kg} / \mathrm{m}^{2} \mathrm{~s} ; \mathrm{x}=0.1\right)$.

Fig. 13. Comparison between the flow visualisation and the liquid-hold-up predicted by the Taitel and Dukler model [28].

Fig. 14. Comparison between the apparent void fraction and the void fraction predicted by the model of Taitel and Dukler [28] for stratified flow. 


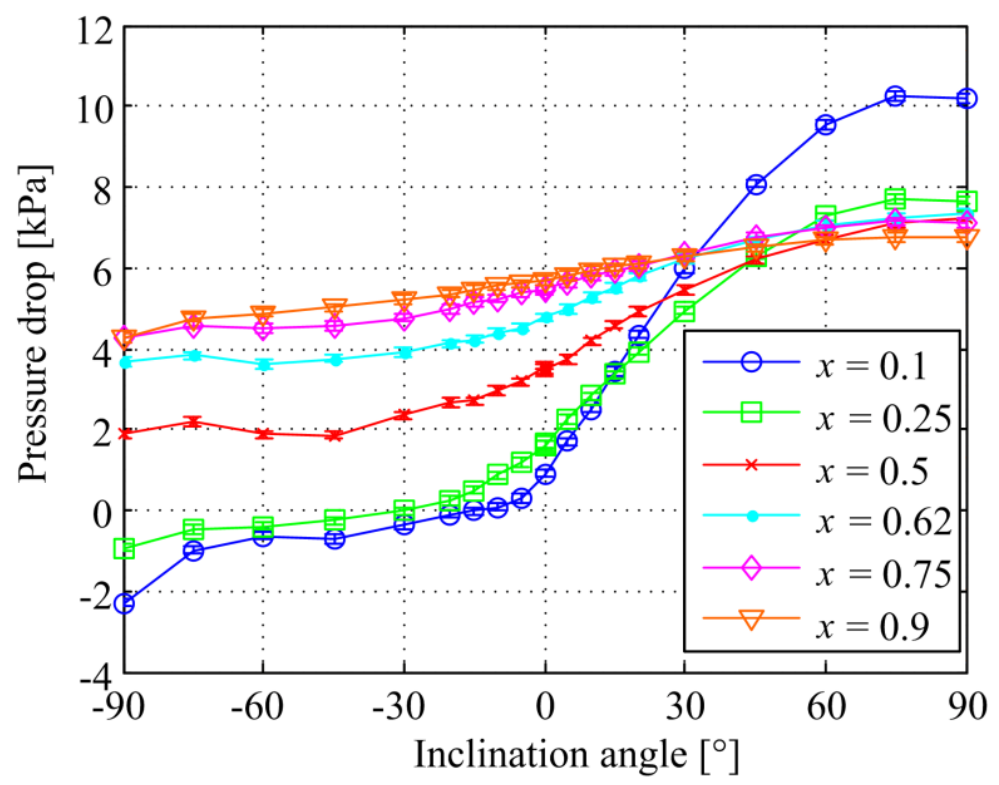

Fig. 1. Measured pressure drops for different vapour qualities $\left(G=300 \mathrm{~kg} / \mathrm{m}^{2} \mathrm{~s}\right)$. 


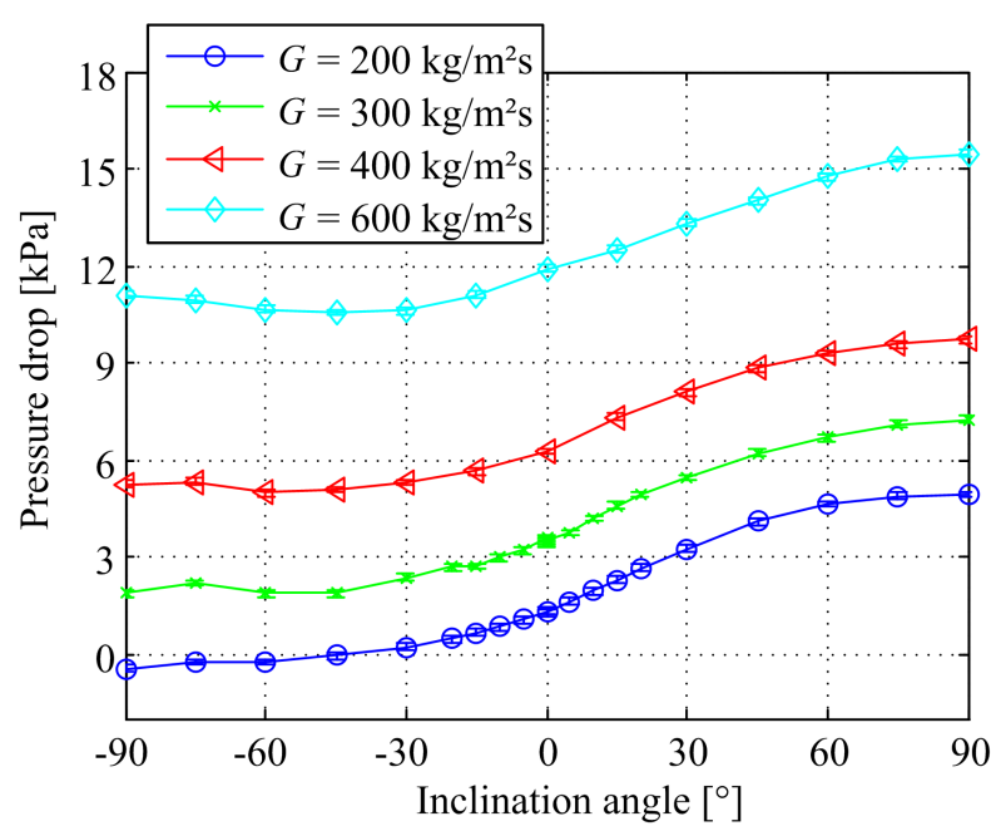

Fig. 2. Measured pressure drops for different mass fluxes $(x=0.5)$. 


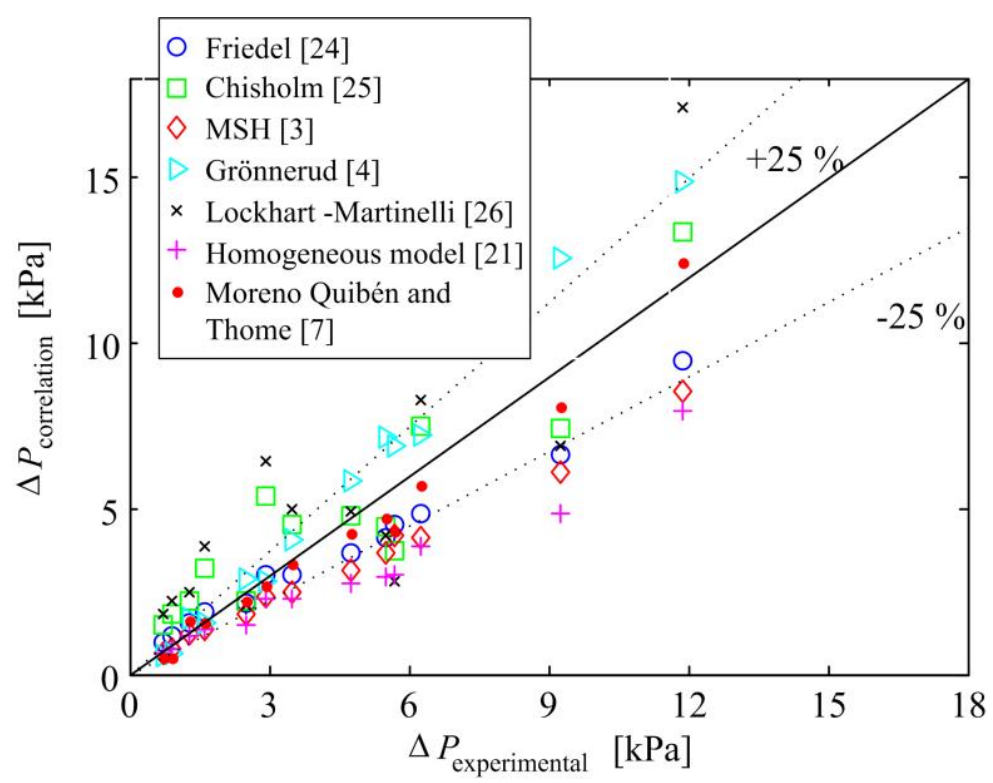

Fig. 3. Comparison of experimental pressure drops with different correlations for horizontal flow. 


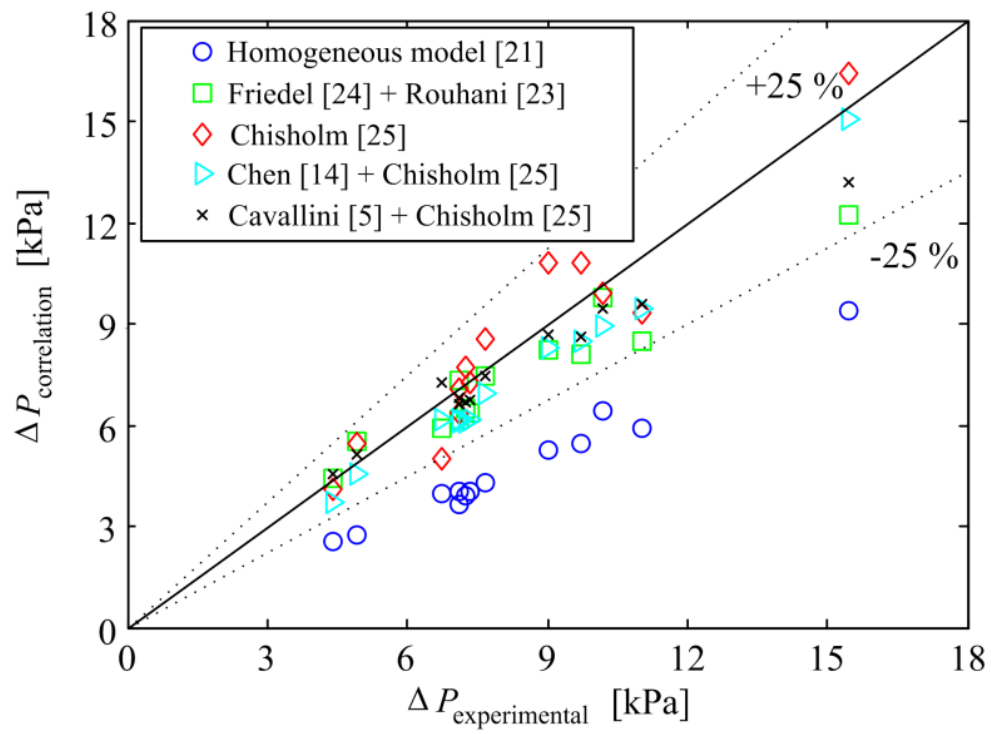

Fig. 4. Comparison of experimental pressure drops with different correlations for vertical upward flow. 


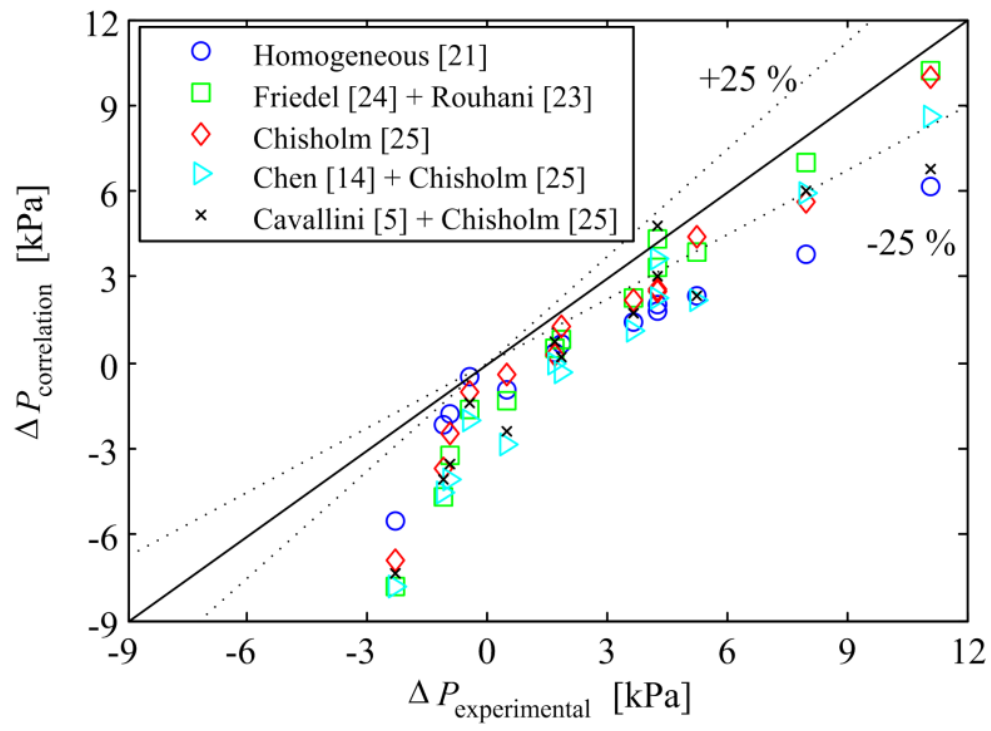

Fig. 5. Comparison of experimental pressure drops with different correlations for vertical downward flow. 


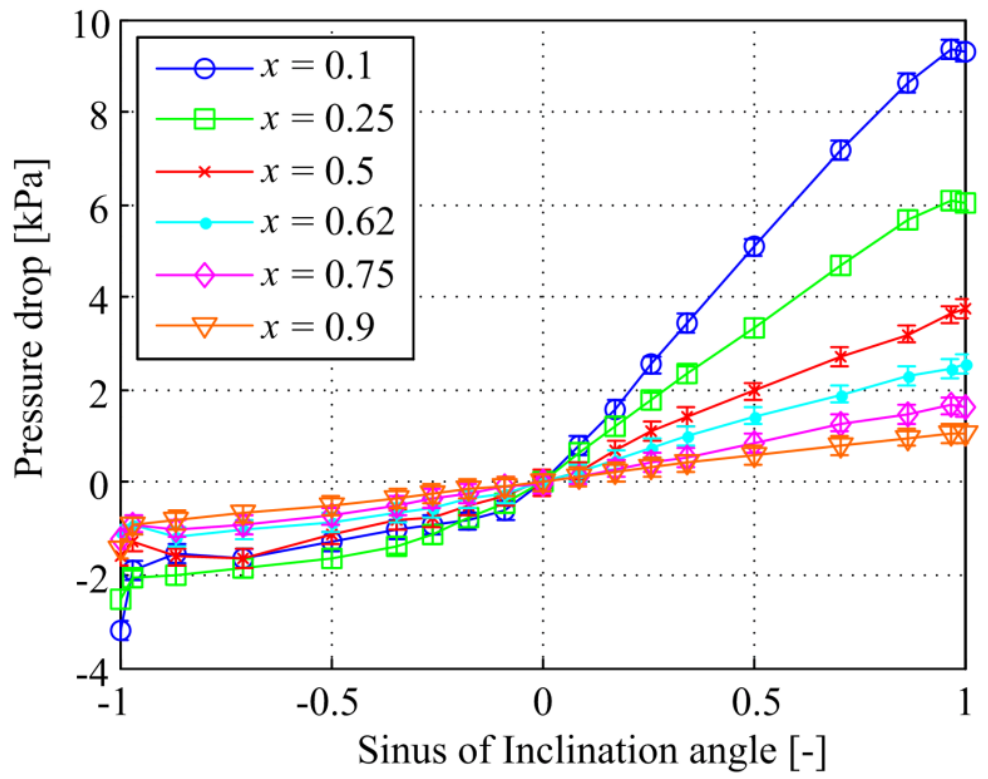

Fig. 6. Apparent gravitational pressure drops for different vapour qualities as a function of inclination angle $(G=300$ $\left.\mathrm{kg} / \mathrm{m}^{2} \mathrm{~s}\right)$. 


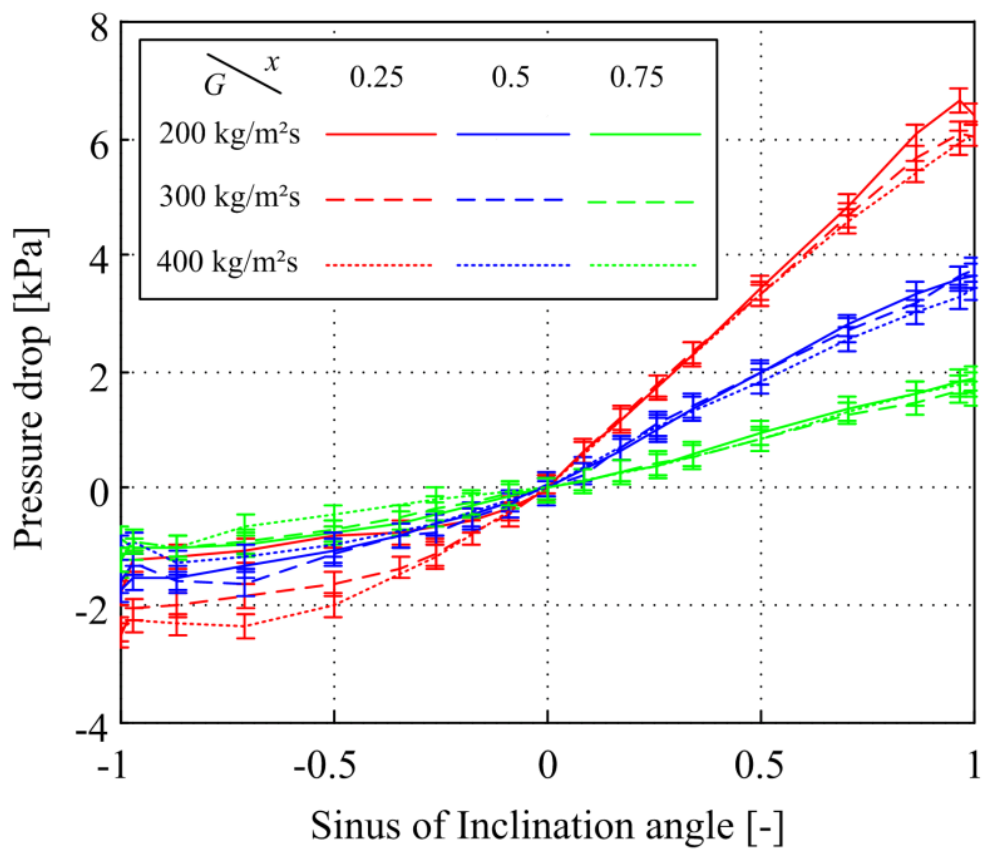

Fig. 7. Effect of the mass flux on the apparent gravitational pressure drop as a function of inclination angle. 


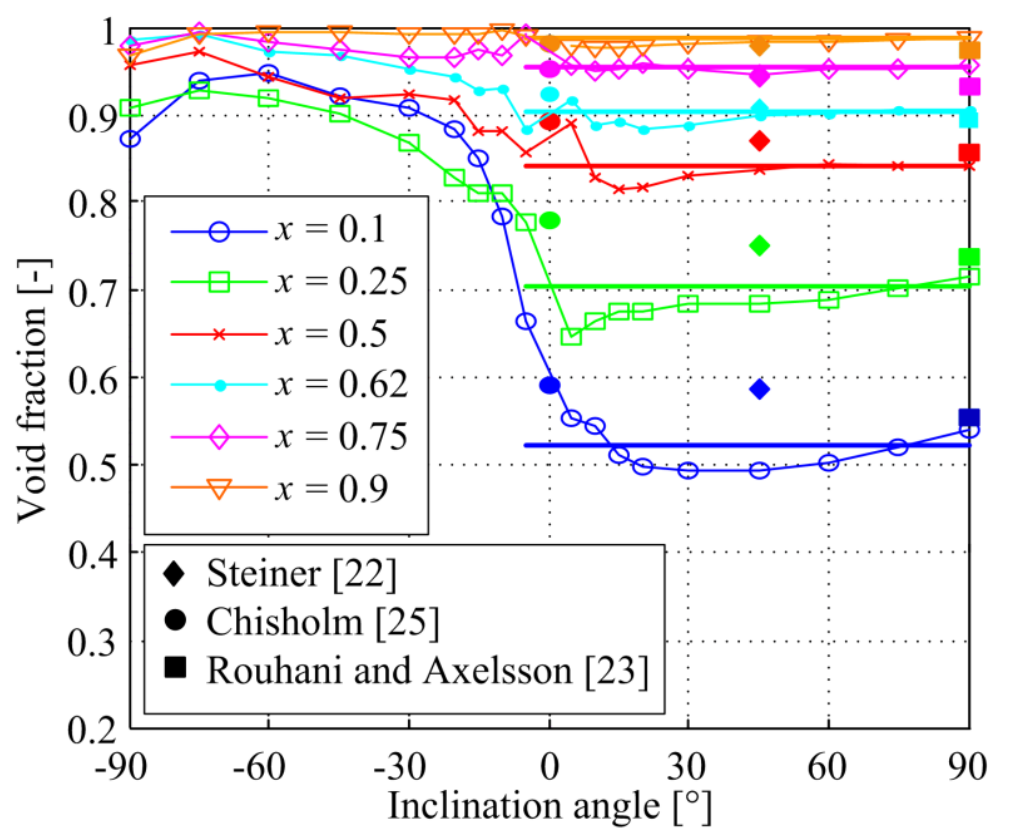

Fig. 8. Effect of inclination angle on the apparent void fraction and comparison with different correlations $\left(G=300 \mathrm{~kg} / \mathrm{m}^{2} \mathrm{~s}\right)$. The thick horizontal lines represent the mean apparent void fraction between $-5^{\circ}$ and $90^{\circ}$. 


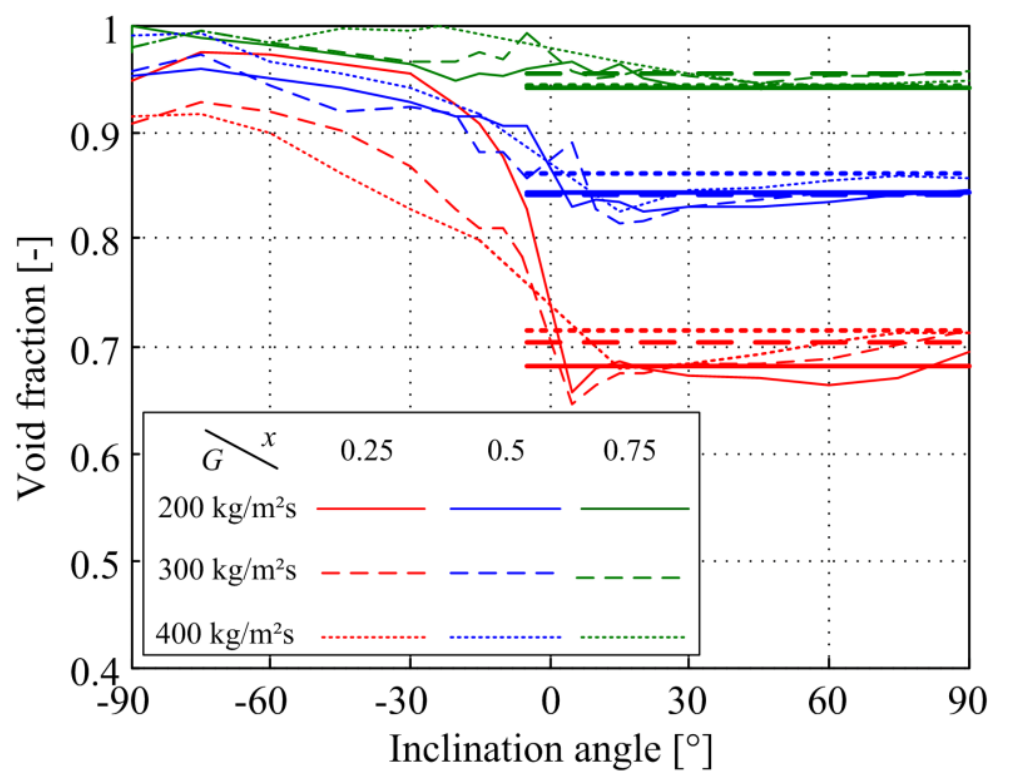

Fig. 9. Effect of the mass flux on the apparent void fraction. The thick horizontal lines represent the mean apparent void fraction between $-5^{\circ}$ and $90^{\circ}$. 


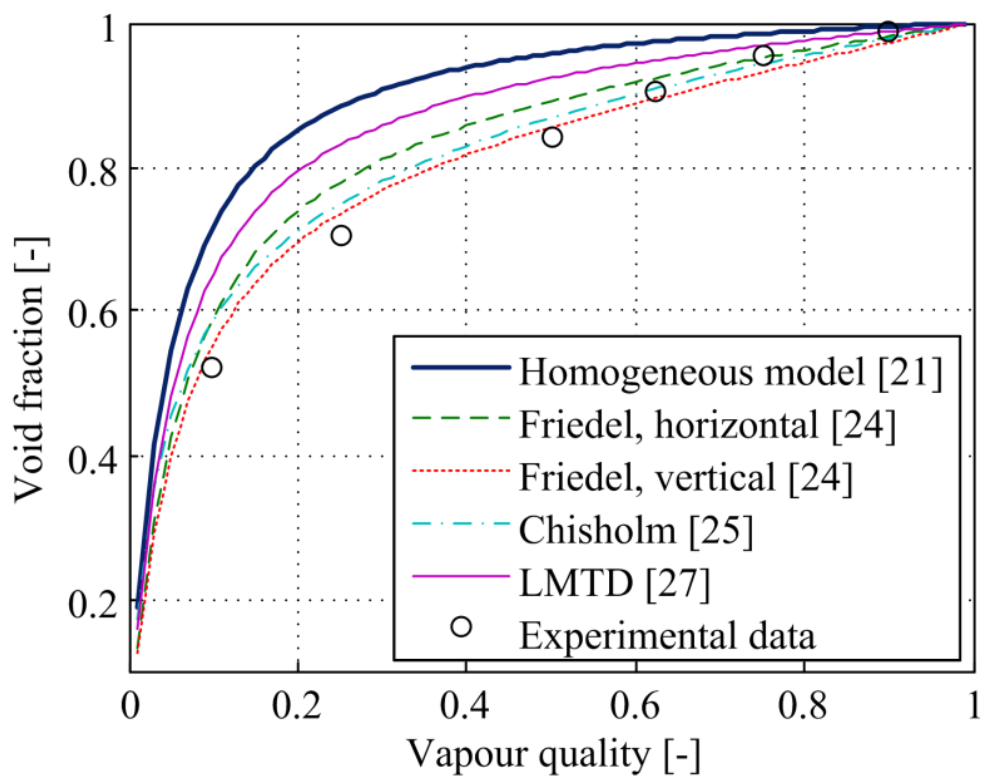

Fig. 10. Apparent void fraction for horizontal and upward flows and comparison with different correlations $\left(G=300 \mathrm{~kg} / \mathrm{m}^{2} \mathrm{~s}\right)$. 


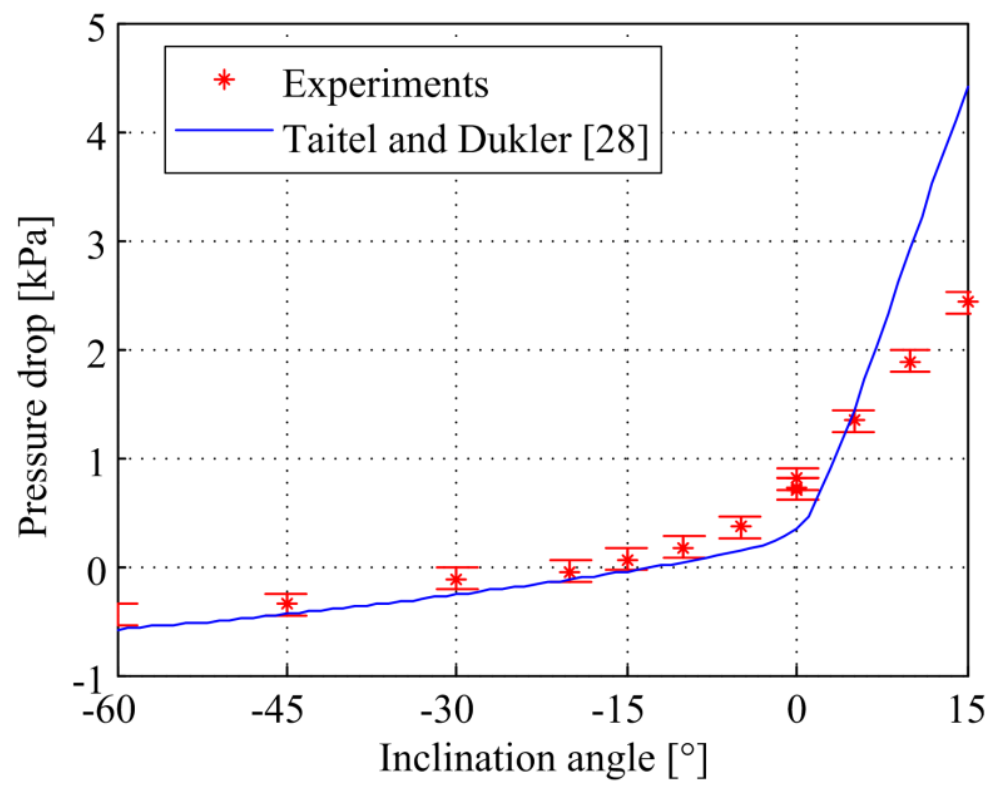

Fig. 11. Pressure drops predicted by the model of Taitel and Dukler compared with experimental results $\left(G=200 \mathrm{~kg} / \mathrm{m}^{2} \mathrm{~s} ; \mathrm{x}=\right.$ 0.25 ). 


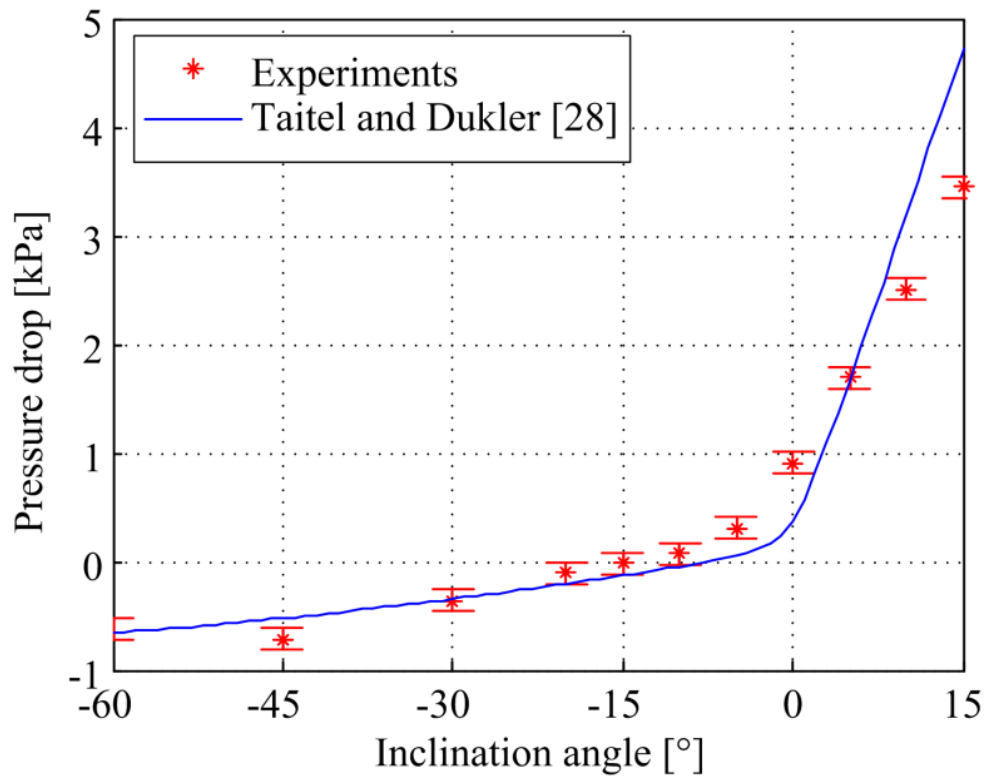

Fig. 12. Pressure drops predicted by the model of Taitel and Dukler compared with experimental results $\left(\mathrm{G}=300 \mathrm{~kg} / \mathrm{m}^{2} \mathrm{~s} ; \mathrm{x}=\right.$ 0.1 ). 
$G=300 \mathrm{~kg} / \mathrm{m}^{2} \mathrm{~s} ; x=0.1$

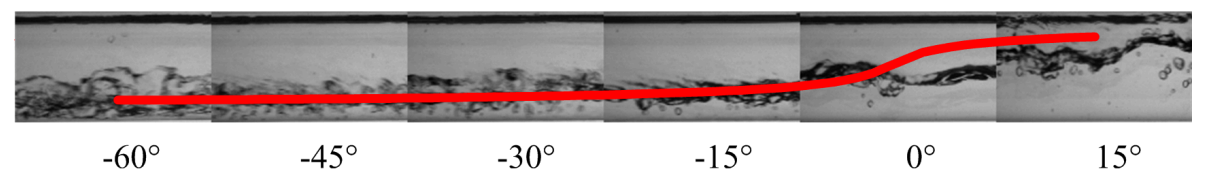

$G=200 \mathrm{~kg} / \mathrm{m}^{2} \mathrm{~s} ; x=0.25$

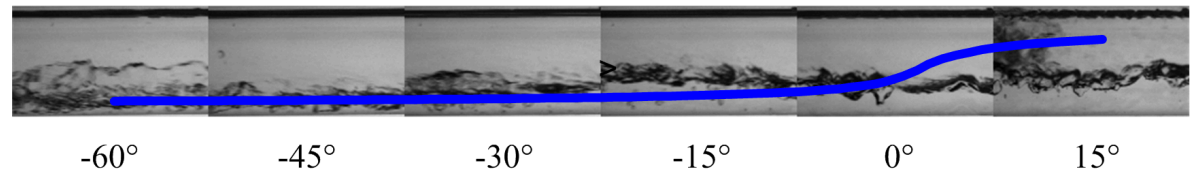

Angle of inclination

Fig. 13. Comparison between the flow visualisation and the liquid-hold-up predicted by the Taitel and Dukler model [28]. 


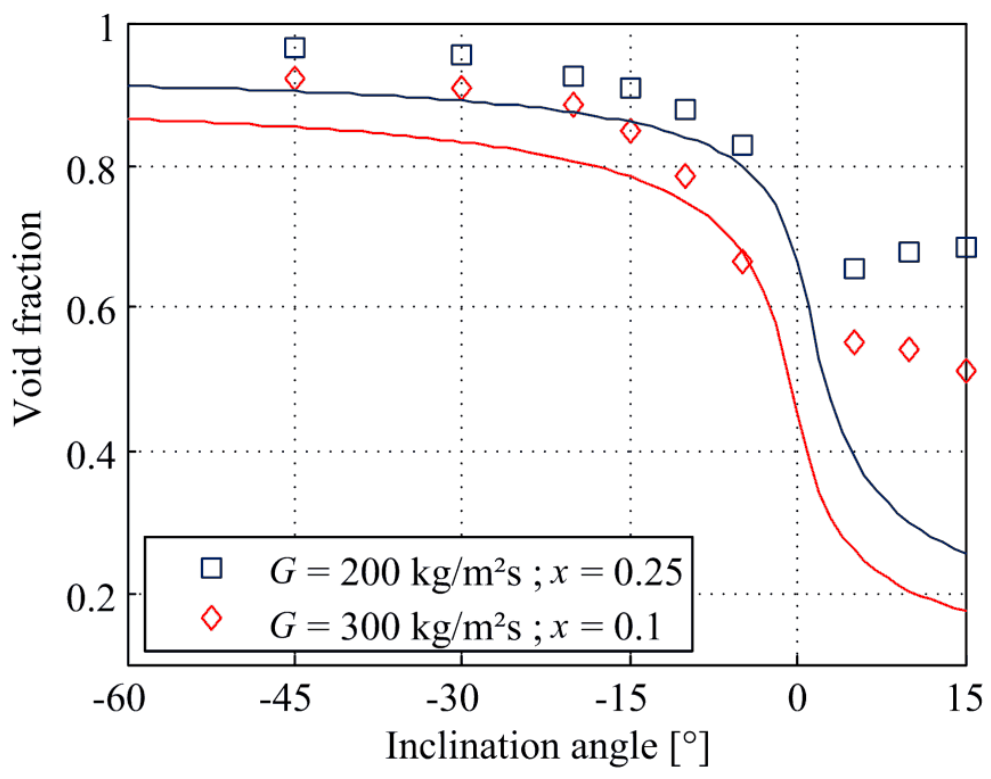

Fig. 14. Comparison between the apparent void fraction and the void fraction predicted by the model of Taitel and Dukler [28] for stratified flow. 